\title{
Non-invasive means of moral improvement - a critical review of selected methods ${ }^{1}$
}

\begin{abstract}
The main purpose of this paper is to underline the importance of non-invasive methods of moral improvement. I defend the thesis that non-invasive stimulation of human morality should not be concerned as outdated. Among different possible methods discussed nowadays, these that do not require any invasive intervention into neural system should remain a valuable part of the discussion about moral enhancement. Two means of non-invasive ways to stimulate morality and their expected effects are proposed in this paper. The first one is derived from the practice of involving horses in the process of resocialization and development of morally desirable traits. The second one is based on the idea of drama-based interventions and its potential of increasing the abilities of perspective taking and noticing morally relevant aspects of situations in the participants.
\end{abstract}

Keywords: morality, moral cognition, moral enhancement, moral improvement, moral education, equine assisted activities, drama-based interventions

\section{Introduction}

Moral enhancement has been an important topic since Ingmar Persson, Julian Savulescu [2008, 2012] and Thomas Douglas [2008] began the debate concerning bioenhancement of human morality. If it is possible to stimulate the human brain in a way that allows people to be more efficient in dealing with more advanced cognitive tasks (cognitive enhancement), why should it not also be possible to enhance moral cognition via a pharmacological substance, such as oxytocin or SSRI [Persson \& Savulescu, 2012]? The answer is neither evident nor shared in academic discussion. What seems to be essential from the methodological perspective, but unfortunately is sometimes omitted in this debate, is the need to explore and understand the complexity and basis of moral cognition and the processes of moral development. It is problematic to support the idea of using pharmacological means, which affect the brain in

${ }_{1}$ I would like to thank dr Michał Klincewicz for constructive criticism, and for his patient guidance, encouragement and advice that greatly improved this paper. I also thank sincerely dr Błażej Skrzypulec for his comments. 
a direct ${ }^{2}$ way, to enhance human morality, without knowing which neural structures and mechanisms underlie the process of moral cognition.

The main purpose of this paper is to show that moral cognition and moral development could flourish with help of indirect methods, especially in the case of individuals with no significant moral deficiencies. Although, when it comes to moral functioning, it is not evident where the line is between an 'average' and 'below average' individual, ${ }^{3}$ it is justified to claim that such a distinction exists, even if it is blurry. This paper aims to identify possible means of moral enhancement understood as an improvement of average moral capacities and not as treatment of individuals with severe moral deficiencies. ${ }^{4}$

However, it is not obvious what should be considered as 'moral capacities' or 'moral dispositions' - their scope and definition highly depend on the adopted ethical framework and the author's approach. Since in this paper no specific ethical system is supported, emphasis is placed on aspects of cognition that are not specific to morality ${ }^{5}$ but are believed to play a significant role in the process of moral cognition and moral functioning. In propositions presented below, the attention is focused on competencies such as perspective taking, empathic concern and the ability to notice morally relevant aspects of situations, which can be considered as important in different ethical systems.

The cognitive-affective concept of moral disposition embraced here derives from the Cognitive-Affective Personality System [Mischel \& Shoda, 1995] and imposes the interpretive approach. Emphasis is placed on the way an individual receives and processes stimuli. Having a specific disposition does not generate a particular behavior. It can rather be characterized by 'If... then...' patterns of processing which result in a specific outcome. Dispositions are believed to be rather stable, but not irrevocable. This gives reason to think that using specific techniques which influence morally relevant aspects of personality could result in a change of the way an individual interprets specific aspects of a given situation and influence his/her behavior. Moral dispositions are understood as complex, dynamic constructs that influence an individual's behavior, interacting with situational factors. ${ }^{6}$

2 The notions 'indirect' and 'direct' can be applied to the field of moral enhancement in two different ways: 1) Direct as invasive / Indirect as non-invasive [Focquaert \& Schermer, 2015 , p. 140]; 2) Direct understood as an action performed in order to change someone's moral beliefs, motives and actions in line with what the enhancer considers as right / Indirect understood as an activity designed to support people in constructing moral ideas, motives or actions, without defining the expected content of these ideas, motives or actions [Schaefer, 2015, p. 262]. In this paper the first approach is adopted whenever the notion 'direct/indirect' is used.

3 The notion 'below average' could be applicable in the case of e.g. psychopaths, individuals with a criminal record or mental disorders that affect moral functioning.

4 The means that could bring the best outcome in therapeutic practice are not discussed here. Even though it is highly possible that in many cases, in the process of moral improvement and treatment, similar practices can be applied, different types of objections might concern each of them.

5 This idea is explained and developed in the following section.

6 See: Klincewicz, Frank \& Sokólska, 2018. 
The central question in this paper is: What kind of practices should be applied to an educational system or raising methods in order to stimulate morally relevant aspects of cognition? In the following paragraph, a novel approach to moral cognition and its neurological background is briefly outlined. The third part of the paper presents examples of different methods of moral enhancement that have been proposed so far. In sections four and five, specific non-invasive methods that have the potential to stimulate moral cognition are given. Recommendations for further studies are presented in the final section.

\section{What to enhance? Morality and its psychological and neurological background}

In this paper, the main line of questioning the idea of moral bioenhancement touches upon its methodology and actual possibilities of application. There is an increasing amount of research showing that in moral cognition both affective and cognitive processes are relevant, and moral judgment is rather the effect of cooperation between rational and emotional processing [Moll et al., 2005; Moll et al., 2008; Van Bavel et al., 2015]. This presumption is sometimes presented in opposition to the dual-process theory, the approach advocated by Joshua Greene [e.g. 2001, 2004, 2015a]. Simply put, this latter theory assumes that moral judgment is the effect of competition between affective and rational processes, in which the former are responsible for deontological choices and the latter lie behind consequentialist decisions. ${ }^{7}$

Moral cognition is increasingly considered as a higher-order process unified at a functional, not a cognitive, level [Moll et al., 2005, 2008; Decety \& Howard, 2013; Greene, 2015b]. It means that there are no cognitive components specific to morality and moral cognition relies on various domain-general processes. It is suggested that research should focus not on separate components of moral cognition but rather on their interactions and the way they affect moral behavior/judgment [Greene, 2015b, p. 41]. There is a high probability that no 'moral faculty' exists and human morality is underlain by numerous different domain-general processes and neural structures [Young \& Dungan, 2012]. Some researchers also emphasize the dynamism of moral cognition and the fact that it is not a linear process but is also affected by external and situational factors [Van Bavel et al., 2015].

The assumption held in this paper is that the indirect stimulation of human morality should not be considered as outdated. As moral cognition involves different areas of psychological and neurological functioning and it is still not clear how specific processes interact, it is difficult to rely on pharmacological substances that aim to affect the human brain directly. Among different possible methods discussed nowa-

\footnotetext{
7 To learn more about this distinction see: Greene, 2015a.

${ }^{8}$ By certain authors, moral faculty is supposed to be a specific mechanism that gathers information from different (non-moral) inputs and, while using computational methods, is about to give moral judgment [see: Mikhail, 2007].
} 
days, these that do not require any invasive intervention on the human brain should be considered as a valuable part of the discussion about moral enhancement. ${ }^{9}$

\section{Different ways to boost morality. Why should we continue to search for betters solutions?}

In numerous publications regarding moral enhancement there is a distinction between invasive and non-invasive methods. Pharmacological enhancement and brain stimulation are placed in the first category, while moral education (e.g. moral dilemmas discussion, character education, etc.) and each practice that does not affect human brain directly (also upbringing and socialization) belong to the second group. This distinction is essential for the debate about moral bioenhancement, its ethical and practical dimension [Focquaert \& Schermer, 2015; Specker et al., 2014]. However, for the purpose of this paper, it is not indispensable to focus on the ethical pros and cons of direct methods. The primary objective here is to focus on the feasibility and potential outcomes of specific means. It should be as transparent as possible which methods are effective and actually could be used to improve moral performance.

In this paper I do not refer, in any significant way, to methods of moral stimulation that are considered as traditional, such as Kohlbergian moral dilemma discussion or character education grounded in Aristotelian virtue ethics. These methods are accurately questioned not only by certain advocates of bioenhancement [Persson \& Savulescu, 2012], but also by some contemporary moral psychologists [Lapsley \& Narvaez, 2005]. For instance, Kohlberg's theory, which focuses on reasoning in moral judgment and decision making and the assumption of phenomenalism, is claimed as empirically inaccurate due to the fact that, according to more recent findings [e.g. Bargh et al., 1996], most judgments are tacit, intuitive and automatic. Indirect methods definitely need to be revised and should be designed in line with current scientific knowledge about moral functioning. Taking into consideration the complexity of moral cognition and the novel, cognitive-affective approach to moral disposition, there is still a room for possibly effective improvement [Klincewicz, Frank \& Sokólska, 2018]. Effective moral improvement practices should influence the way an individual interprets the reality, on the conscious and unconscious level, through affecting his/ her cognitive-affective system and its units significant to moral cognition.

The latter statement might be questioned, since influencing someone's morality independently of his/her will can be considered as immoral in itself. On the other hand, the lack of willingness to become morally better also might be seen as immoral. Even though these questions are important in the moral bioenhancement debate, the choice between these two approaches is not very relevant in the context of this paper. However, certain properties of non-invasive methods make them more acceptable than invasive methods, even if the choice between these perspectives is not evident. First of all, affecting the way 'an individual interprets the reality, on the conscious and unconscious level' does not imply that the process itself is happening against

\footnotetext{
9 See: Klincewicz, Frank \& Sokólska, 2018.
} 
the subject's will. Most of the non-invasive methods require active participation on the part of the individual in the process of developing dispositions and there is no reason not to inform the subject what the purpose of the intervention is. It is more problematic in the case of small children. However, in a lifetime, various factors will alter the individual's cognitive-affective system, often without his/her knowledge. If we assume that using educational or raising methods that influence someone's way of interpreting, also on the unconscious level, is immoral, there is no room for any educational or parental practices, even these that are not related to morality. It is linked to another aspect of non-invasive means: they do not influence moral cognition in isolation from the development of other social/cognitive abilities. In opposition to moral bioenhancement, in non-invasive methods outlined below emphasis is laid on the development of different cognitive units, also these that involve reasoning. In view of the above, it can be supposed that in most cases the individual will participate in moral improvement programs not against his/her will and, at the same time, willing to become morally better.

The solutions proposed below and expected outcomes of their usage are grounded in recent studies of moral cognition and development in neuroscience and psychology. Within the framework of current knowledge, they could probably serve as effective means to enhance morality via stimulating its components ${ }^{10}$ such as perspective taking, empathic concern or self-awareness. The first one rely on the bond between man and animal, while the second one refers to the concept of interactive theater.

\section{Animal Assisted Interventions as a feasible way to improve moral capacities}

There are already some studies indicating that the involvement of animals in therapeutic and rehabilitation programs is evidently beneficial [Kohl, 2012; Nurenberg et al., 2014; Andreasen et al., 2017]. Some of them refer to the impact of animal presence on the development of morally relevant features, such as empathy, sense of responsibility and sensitivity to other people's needs and feelings. There are studies indicating that similar regions in the brain are activated while seeing humans and animals in distress [Franklin et al., 2013]. These results suggest that the abilities gained during interaction with animals might reflect in the attitude toward people. ${ }^{11}$ With this in mind, it seems justified to expect that using animals in moral enhancement programs can be beneficial to both treatment and improvement. Various examples can be qualified under this approach, such as dog therapy, feline therapy or equine assisted therapy. In this paper the focus is placed on the last one.

\footnotetext{
${ }^{10}$ As 'components' I understand here mechanisms/abilities that play a significant role in moral cognition. However, the fact that they are not moral per se, in isolation from other elements, must be taken into account while designing moral improvement means.

${ }^{11}$ Despite this promising outcome, it is necessary to be cautious and not to treat these results as a confirmation that we can certainly translate an attitude toward animals into an attitude toward people. More studies need to be done to verify this hypothesis.
} 


\subsection{Benefits of Equine Assisted Activities}

For the purposes of this paper the following notions are implemented: Equine Assisted Psychotherapy/Therapy (EAP/T) and Equine Assisted Learning (EAL). The latter method (EAL) is the most appropriate when it comes to moral improvement, because this approach applies to individuals with no significant psychological or physical deficiencies. However, since moral improvement, at least partially, focuses on enhancing competencies that are also the target of the resocialization process, it seems justified to refer to the concept of EAT as well. Equine Assisted Learning is defined as “(...) an experiential learning approach that promotes the development of life skills for educational, professional and personal goals through equine assisted activities." ${ }^{2}$ In turn, the definition of Equine Assisted Therapy is "(...) treatment that incorporates equine activities and/or the equine environment. Rehabilitative goals are related to the patient's needs and the medical professional's standards of practice." ${ }^{13}$

On the basis of various publications, Hannah Louise Burgon [2011] points out that horses are claimed to provide benefits such as being non-judgmental and motivational. They help in building self-esteem, confidence, and they are believed to be effective in building trust and attachment. Everyone who has ever interacted with horses is aware of their sensitivity and the necessity of staying calm and confident when interacting with them. Horses have developed a highly effective system of communication based on body language and have a great ability of 'picking up' on human emotions and intentions. The latter is connected to one of the most relevant advantages of horses when it comes to changing patterns of interpretation: they can be used as a metaphor. To shed some light on this feature, it will be helpful to use an example. ${ }^{14}$ For instance, when someone approaches a horse and the animal walks away or shows a fear response, it can impact the individual's perception of his/her own social interactions. A person perceives the horse's behavior via his/her own patterns of interpretation and, with the help of a 'mentor/therapist', should be able to relate it to his/her own style of acting in relationships with others. After getting the knowledge of 'what went wrong', the next attempt to approach the horse, in a different way, can result in a positive response. It is claimed that these interactions with horses should result in a development of self awareness and a shift in the way the individual functions in relationships. A summary of the most important benefits of equine assisted activities in the field of moral cognition and moral development is given in the following paragraphs. ${ }^{15}$

\footnotetext{
${ }^{12}$ The definition of the Professional Association of Therapeutic Horsemanship International (PATH Intl.).

13 Ibid.

14 Source: http://www.eyeofahorse.com/news/florida_today/florida_today_horse_sense_pg2.pdf.

15 It is necessary to mark that there is still very little amount of scientific studies that provide a credible evaluation of short and long term effects of the mentioned methods.
} 


\subsection{Equine Assisted Activities as a moral improvement means}

As regards the question of therapeutic practices related to moral enhancement, horses were used e.g. in the therapeutic horsemanship ( $\mathrm{TH})$ program for 'at-risk' young people and equine assisted psychotherapeutic practices applied in order to reduce aggressive behavior in psychiatric inpatients. These two types of activities are discussed here with emphasis on morally relevant features/mechanisms they are about to affect.

The therapeutic horsemanship program for 'at-risk' young people is one of the numerous equine assisted solutions meant to help young individuals exposed to factors such as poverty, neurological disorders, dysfunctional families, neglect ${ }^{16}$ and sexual or psychological abuse [Burgon, 2011], which could put them at a higher risk of having different psychosocial problems in the future. The lack of a sustainable, safe environment during childhood and neglect are linked with significant alterations in brain development, both structural and functional [Bick \& Nelson, 2017], tendencies to adopt behavior concerned as immoral, a different way of processing morallyladen stimuli and decreased moral sensitivity [Escobar et al., 2014; Decety \& Howard, 2013]. Despite all this, neuroplasticity enables a shift in the patterns of cognitive/ emotional processing [Bick \& Nelson, 2017] and through social impact, appropriate care or therapy there is an opportunity to change the way individuals perceive specific situations and the manner they act. It is highly probable that certain programs designed to help 'at-risk' children not only influence their general life skills, but also affect the way they process morally-laden stimuli and their competencies to act in a morally desirable way.

Focusing on projects involving horses, it is also possible to point at the aspects of moral cognition that these activities could enhance. For instance, some authors claim that EAT helps to develop empathy. Although there is no agreement on the relation between morality and empathy, the definition of empathy is not shared among different authors, and the outcome of 'empathic response' is not always the most desirable,$^{17}$ some aspects of empathy could be targeted in moral improvement interventions. The concept of empathy adopted here is the one proposed by Jean Decety and Jason Cowell [2014a, 2014b]. They distinguish its three components: emotional sharing, empathic concern and perspective taking. Among them, the last two are the most important for moral cognition. Empathic concern is claimed to have a motivational role, while perspective taking is a cognitive facet. In isolation, empathic concern does not always influence moral judgment in a good way since it is usually displayed toward relatives or in-group members. According to Decety and Cowell [2014b], it is perspective taking that allows to extend empathic concern from in-group members to all humanity. However, it is believed that the flawed ability to experience empathic concern is one of the characteristics of psychopaths that influences their moral behavior and moral

${ }_{16}$ Parental care during childhood is considered to be one of the most important factors in moral development. For more information see: Christen \& Narvaez, 2012; Eisenberg, 2000; Cowell \& Decety, 2015.

17 See e.g.: Prinz, 2011. 
judgment [Decety \& Yoder, 2016]. Decety and Cowell [2014a, p. 338] refer to research showing that there is a link between impaired empathic concern and inability to experience moral emotions (e.g. guilt and remorse), as well as being indifferent toward the welfare of others. They indicate vmPFC as the hub for empathic concern and moral behavior. In view of the above, it seems justified to claim that a supervised enhancement of empathic concern will presumably result in a positive outcome in the case of moral improvement.

Although EAA are rather believed to increase empathic concern (e.g. via attachment), interactions with horses are slightly different than those with cats or dogs. Horses are big and unpredictable animals (at least for a person who has had no experience with them) and it is necessary to understand why they behave in a specific way, for example, why they might be scared or withdrawn in certain circumstances. It is likely that EAA might improve not only empathic concern, but also perspective taking. However, even though this possibility seems very promising, given that there are no significant studies confirming this supposition, it is better to be cautious about this link. Burgon [2011] ${ }^{18}$ points at empathy as one of the most important aspects influenced by EAT. Even though she employs a general concept of empathy, it can be concluded from her report [Burgon, 2011, pp. 174-176] that she refers to both empathic concern and perspective taking. For instance, she cites an example of a young girl who developed caring feelings and behavior toward the oldest horse in the herd, being concerned about his needs and health and sacrificing most of her time for him (empathic concern). In the case of another horse, which was scared and anxious, she could explain what the horse may have felt and which actions could ease his nervousness (perspective taking). Another girl responded to the fear of the anxious horse by giving him support and then claiming that she had felt that this horse needed her more than the one that was calm and not nervous (empathic concern). One of the boys understood the anxiety of a mare being separated from the horse she was attached to (perspective taking), and tried to comfort her. These examples, even though very limited, show the way interacting with horses can influence the way people act and perceive. What needs to be evaluated is, among other aspects, the way the attitude toward horses translates into one's approach to humans.

The other example of EAT discussed in this article might seem more controversial in the case of moral improvement of 'average' individuals. This is a study meant to assess the effectiveness of EAP in reducing aggressive behavior in chronic psychiatric inpatients. However, the assumption that horses, as bigger animals, could be more effective in decreasing aggressive behavior than pets [Nurenberg et al., 2015, p. 80] makes it possible to think that the results of this research might also be partially relevant in the case of healthy individuals. What is more, the activities adopted in this program were designed in accordance with the standards of the EAGALA association, which incorporates horses in both mental health treatment and personal development. ${ }^{19}$ The purpose of this study was to compare the impact of EAP, CAP

\footnotetext{
${ }^{18}$ This research was conducted with a small group (7 participants), using only qualitative research methods (interviews and participant observation), so there is no way to generalize the result. It can only indicate directions that further studies can follow and explore.

19 Source: http://www.eagala.org.
} 
(canine assisted psychotherapy) and SSP (social skills group psychotherapy) on violent behavior and related symptoms three months after the end of the program. In total, 90 inpatients with registered violent acts in their records took part in this project. The study showed that in comparison to other methods, EAP shows a significant decrease in both violent incidents and secondary-aggression related measures [p. 84]. The authors speculate that the better results of EAP might be caused by the fact that horses are large animals, potentially able to harm, but not doing it. There is a chance of modeling non-violent reactions in provocative situations. They also highlight the aspect of 'mirroring' human responses, which might be unique comparing to other popular forms of AAT [p. 85].

As mentioned above, besides therapeutic practices, horses are also involved in activities with people with no significant mental disabilities or adaptive problems. Major fields where EAL is proposed are education, corporate/professional development and coaching/personal development. ${ }^{20}$ Unfortunately, there are even fewer reliable sources evaluating the results of these projects, especially their morally relevant aspects, than in the case of EAT. One example was chosen to be cited, even though it was not directly focused on moral improvement. It was a program meant to improve adolescents' social competence and behavior [Pendry et al., 2014]. This project was meant to perform a preventive function. The authors highlight the fact that activities aiming at strengthening specific competencies in the youth (behavioral, social, etc.) result in better performance in adulthood [pp. 281-282]. A randomized controlled trial was used in order to verify the influence of equine assisted activities on child social competence and behavior. The results showed a moderate positive effect in the case of strengthening competencies (personal responsibility, decision making, goal-directed behavior, self-awareness, self-management), and a positive correlation between the number of attended workshops and the increase in positive and decrease in negative behavior [p. 290]. Most of these aspects are also, more or less, relevant to moral cognition. We do not have sufficient data to conclude to what extent the mentioned features could influence moral performance, for instance, if the positive effect on the decision making competence is also relevant in morally-laden situations. However, taking into consideration different sources, it might be assumed that there is a potential for moral improvement in using EAA.

It is important to shed light on difficulties that this method faces. Horses are big, sensitive animals and educational/therapeutical contact with them is not supposed to be suitable for everyone. Besides, not each horse is appropriate to take part in such a program. Even without considering these constraints, accessibility of equine assisted activities to average people is very limited. Maintaining a horse generates a lot of costs and requires adequate space. In the case of activities involving a group of individuals, at least a few horses are needed since direct contact is the most beneficial. Unfortunately, it is rather impossible that EAA might be used on a large scale and become available to everyone. Despite this fact, the method is very promising and even if extensive application is not very realistic, further studies should be conducted in order to implement it under right circumstances.

\footnotetext{
${ }^{20}$ Source: https://www.pathintl.org/60-resources/efpl/1029-learn-about-eaat-equine-assisted-learning.
} 


\section{Drama-based methods as a moral improvement means}

Various types of drama-based interventions are about to provide different benefits for participants and, looking at the bigger picture, also bring about a social change. Unlike EAA, drama-based methods do not require high costs or appropriate space. These methods are as promising in moral improvement as involving horses, while being a lot more accessible to average individuals. It is claimed that drama-based activities affect e.g. moral awareness, moral behavior and moral understanding, and allow individuals to notice and respond to moral concerns more efficiently [Day, 2002; Winston, 1999].

In this paper, emphasis will be placed on one of several types of interactive theater: Forum Theatre. It is suggested here that Forum Theatre might be a right tool in aiming not only at social or political change, but also at moral improvement. However, since there is not enough researche on the impact of this specific technique on moral functioning, other drama-based activities relevant to this field are also discussed.

\subsection{Forum Theatre and its impact on morally relevant features}

As a form of the Theatre of the Oppressed, Forum Theatre was created by Augusto Boal and originally was meant to bring about a social and political change. Oppression is understood here as various forms of dominance, exclusion or exploitation [Gourd \& Gourd, 2011]. In this kind of performance there are always characters who are abused in a certain way and their oppressors. Importantly, Forum Theatre refers to the concept of simultaneous dramaturgy, where the division between actors and spectators is affected. During the replay of a performance, each member of the audience - a 'spect-actor' - can stop the play and not only suggest a solution, but also 'become' one of the characters and show his/her way to overcome the oppressive situation presented [Boal, 1979].

As regards the influence of Forum Theatre on moral cognition, the key notion is probably perspective taking. Different authors defined it in slightly different ways. The concept of perspective taking is usually linked with empathy and theory of mind (TOM). As mentioned in the previous section, it can be characterized as the cognitive component of empathy that allows a person to put him/herself in another individual's body and imagine what that person could think or feel [Decety \& Cowell, 2014b, p. 530]. In the case of TOM, sometimes both concepts are used interchangeably, however, they should rather not be perceived in this way. TOM is an ability to attribute specific mental states to oneself and others, while perspective taking is an ability to put oneself in 'other people's shoes'. Sometimes empathy is recognized as emotional perspective taking, while TOM as cognitive perspective taking. Since these interpretations are not totally accurate, here a different approach is applied. Perspective taking should be identified with neither empathy nor TOM. In the case of interactive theatre, the most important property of perspective taking is the ability to understand and feel the situation of others, and then to perceive the reality and act with patterns of interpretation affected by this specific experience of being in 'someone else's shoes.' The development of perspective taking understood in these categories might be 
expected as a major outcome of Forum Theatre and one of the effects of other dramabased activities.

\subsection{Drama-based methods as moral improvement means}

Similarly to EAA, there is little amount of scientific research measuring the influence of Forum Theatre (or other drama-based techniques) on moral improvement. Below, examples highlighting the impact of theater-based workshops on attitudes toward two different morally relevant topics are presented. One of them is genderbased violence and the other one is the problem of bullying.

In the case of sensibility to the phenomenon of sexual assault and its psychological and physical consequences, two cited studies indicate a positive outcome of Forum Theatre workshops. The research conducted by José I. Rodríguez et al. [2006] shows that, comparing to participation in a sexual assault lecture (or to the control group), taking part in a slightly modified version of Forum Theatre classes [pp. 235-238] resulted in, among others, increased perspective taking and empathic concern toward potential victims of this kind of abuse [p. 245]. What is also interesting, the higher ability of perspective taking and empathic concern also resulted in a greater propensity for comforting harmed individuals, while increased emotional contagion did not imply this effect. ${ }^{21}$

Karen S. Mitchell and Jennifer L. Freitag [2011] explored the influence of Forum Theatre on bystander responsibility and victim blaming in the case of sexual assault. Similarly to the previous one, their approach was meant to change the social structures that allow gender violence to happen [p. 991]. ${ }^{22}$ They used the concept of Forum Theatre for Bystanders (FTB), where the spect-actor does not replace the protagonist another individual: the witness of gender violence. ${ }^{23}$ The purpose here was to build a responsible community efficient in preventing sexual assault from happening. The importance of being conscious of the responsibility for the solution of a specific problem and the pledge to help were highlighted [p. 1001]. In their paper, the authors rarely refer to the notion of perspective taking, but rather to possibilities that dialogue, strong community, increased awareness and appropriate intervention skills could bring out via interactive theater workshops. In the context of bystanders and their ability to recognize morally relevant situations, another interesting method was presented in this paper. The spectators watched a play and they were asked to yell "Stop!" each time they noticed anything that could be violent. After interrupting the play, the person had to explain what he/she considered as violent [p. 1005]. Although this technique would probably be less effective in the context of perspective taking,

${ }^{21}$ Simple emotional contagion might result in personal distress, which is usually negatively related to prosocial intentions/behavior [e.g. Eisenberg, 2000].

${ }^{22}$ In both studies the authors pay attention to the problem of offenders and bystanders, not a victim itself. Comparing to techniques that teach women to avoid sexual assault, this approach is more accurate because the source of the problem is targeted.

${ }^{23}$ It is claimed here that this scenario could help in taking the responsibility for this act over from the victim to a bystander [p. 1001]. This is an interesting observation, however, 'wearing the shoes' of a victim does not have to lead to victim blaming. More research is needed in this area. 
it has a potential to stimulate different aspects of moral cognition, such as noticing problems and reacting to them.

Bullying ${ }^{24}$ is another issue that drama-based activities have a chance to influence. Sometimes bullying can be directed at an individual who is weaker, new in a specific environment or just at some point different from others, as in the case of bullying in school or workplace. However, it can also be directly related to factors such as one's race or sexual orientation. There are already some studies indicating the effectiveness of theater-based activities in decreasing bullying-related acts and attitudes in a specific environment, such as school [Gourd \& Gourd, 2011; Jaronen et al., 2012]. Certain studies focus on the influence of this method on the situation of specific groups, for instance the LGBTQQ community [Wernick et al., 2016].

The evaluation of a school-based drama program applied in a Finnish primary school [Jaronen et al., 2011] showed that theater workshops were effective in decreasing bullying-related behavior in the targeted group (10-11-year-old children). In this study, drama activities ${ }^{25}$ were supported by activities at home and meetings with parents. 190 participants (answers from 134) were involved in this program, being assigned to the experimental and control groups. A pretest and posttest were conducted in both groups. The results showed a significant decrease (more than 20 percent units) in self-reported bullying victimization (being bullied) in the case of the intervention group. At the same time, in the control group victimization decreased slightly (1.6 percent units). It is important to mark that in the case of bullying (being a bully) the difference between the control and experimental groups was not significant. Self-reported bullying decreased by 5.9 percent units in the experimental group and increased by 1.6 percent units in the control group [Joronen et al., 2011, p. 11]. In this study, a self-completed questionnaire form was used, so it is possible that children who participated in this research were not eager to admit that they bullied others. There is a difference between the two effects (in bullying and in victimization), however, we can assume that the influence of theater-based activities on bullying related issues is visible, since during the posttest significantly fewer children reported being a victim of this kind of harassment.

Also in the case of increasing the intention to advocate for LGBTQQ people, drama-based interventions showed significant effectiveness [Wernick et al., 2016]. The researchers did not use the Forum Theatre method, but a combination of scripted performances, prepared on the basis of personal experience of the participants, and post-performance dialogue [p. 191]. The purpose of this study was to check the effectiveness of the mentioned method in raising awareness and advocacy around the LGBTQQ community. Like in FTB, emphasis was laid on the role of bystander and his/her ability to notice situations when someone's rights or/and well-being are violated. People should be able to detect problems, have a motivation to react and a competence to act in the most proper way [p. 190]. These scheme is also applicable to other morally-laden situations, which makes this study relevant also in a broader context. The answers from 515 high school students were gathered in this research. There

\footnotetext{
${ }^{24}$ By 'bullying' I understand all forms of repetitive verbal, physical or emotional violence, aiming to abuse, dominate and terrorize others.

${ }^{25}$ Forum Theatre was not applied here.
} 
was a noticeable increase in the willingness to advocate and intervene in situations of LGBTQQ harassment. The authors assumed that intervention on the individual level could lead to actions on the structural level [p. 197]. If drama-based workshops can influence this link, there is a chance that it might also work in other morally relevant situations. These activities could help individuals not only put more attention to specific acts of violating moral rules, but also make right choices and advocate for change on the macro-level. Nevertheless, this is yet an assumption and more research is needed to see if this dependency actually exists.

The drama-based methods of moral improvement also face certain challenges. Since theatre performances still have not been used widely as moral improvement means, their effectiveness is still a presumption. However, the examples presented above give grounds for expecting that this kind of activities might be an adequate solution in moral education of both children and adults. Especially Forum Theatre and its alternative versions have the potential to impact the perspective taking capacity. We can assume that carefully designed workshops, with a precise objective, might be a way to achieve the desired improvement.

\section{Conclusions and recommendations for future research}

The main objective in this paper was to discuss means of moral improvement that could be an alternative to both traditional methods and moral bioenhancement. Taking into consideration the complexity of moral cognition, its dynamism [Van Bavel et al., 2015] and the fact that, with high probability, it is unified on the functional and not cognitive or biological level [Moll et al., 2005, 2008; Decety \& Howard, 2013; Greene, 2015b], it is highly questionable if any pharmacological substance could impact it in the desired way. Various, often non-moral, factors influence the process of moral cognition during the life-cycle of an individual.

The examples outlined above are promising in the context of moral improvement, since they are more accessible, much safer and face fewer ethical and methodological doubts than pharmacological means. Nevertheless, some concerns about both means discussed in previous paragraphs remain. First of all, it is necessary to create specific programs that will meet the requirements of the moral improvement process and target morally relevant aspects of cognition. In the case of EAA, it concerns mainly the sense of responsibility, empathic concern and perhaps perspective taking. Theatrebased activities could be a tool for enhancing perspective taking and the ability to notice morally-relevant aspects of situations. ${ }^{26}$

Methodological challenges are apparent in both cases, since the effectiveness of these methods has not been examined yet in a systematic way. The process of designing specific techniques is challenging, just as much as finding an accurate way of evaluating specific means. The short and long-term effects of particular interventions should be measured in order to establish if and how often particular methods should

${ }^{26}$ These are initial assumptions and it is possible that different morally relevant features might be influenced by various forms of these interventions. 
be applied. In addition to psychometric tests and participants' relations, techniques measuring changes on the biological level should also be used in the evaluation process. These may be neuropsychological imaging techniques, such as EEG and fMRI, or classic psychological measures, such as electrodermal activity (EDA).

It is also worth noting that besides the methodological challenges there are also other challenges, relevant in the context of practical application. Two of them are shortly discussed here. Firstly, a question that often appears in the moral enhancement debate touches upon normativity. Certain authors claim that moral enhancement means should be designed in accordance with a specific ethical system, while others see a possibility of applying techniques which improve features underlying moral cognition. Natasza Szutta [2015] distinguishes between directive and non-directive methods of moral education. The first concept refers to methods in which specific values and beliefs are transmitted in a learning process. Non-directive methods, on the other hand, imply a presumption that individuals should receive only 'tools' that let them find the values and norms they want to follow. Methods described in this paper lie somewhere in between these two approaches. Major ethical systems agree on certain moral rules, such as upholding human dignity and not hurting others intentionally. The implementation of these standards and the outcome may differ, depending on the adopted normative system. The way the methods suggested above are meant to be applied, especially the drama-based techniques, and the 'content' of a specific program, might be used also as a means to educate in accordance with a particular ethical system. However, generally they are rather aimed at effecting change on the cognitive-affective level and at developing morally relevant dispositions.

The other challenge is closely related to that last point. The answer to the question of what exactly should be influenced by moral enhancement methods is also debatable. Since moral cognition is seen as a complex process involving various cognitiveaffective mechanisms, it is not obvious what exactly should be the target of these interventions. For instance, Persson and Savulescu [2012] point at altruism and the sense of justice as the most important moral dispositions. In this paper, attention is focused rather on particular competencies, such as perspective taking, empathic concern and the ability to notice morally relevant aspects of situations. Certainly, there is still a lot to explore in the field of moral cognition and moral functioning. In the context of moral enhancement/improvement, it is mostly about analyzing the relation and dependencies between distinctive morally relevant features and the way they affect the processing of morally-laden stimuli, decision making and behavior. This knowledge should help match methods to specific individuals or groups successfully.

\section{BIBLIOGRAPHY}

Andreasen, G., Stella, T., Wilkison, M., Szczech Moser, C., Hoelzel, A., \& Hendricks, L. (2017). Animal-assisted therapy and occupational therapy. Journal of Occupational Therapy, Schools, \& Early Intervention, 10(1): 1-17. 
Bargh, J.A., Chen, M., \& Burrows, L. (1996). Automaticity of social behavior: Direct effects of trait construct and stereotype activation on action. Journal of Personality and Social Psychology, $71(2): 230-244$.

Bick, J., Nelson, C.A. (2017). Early experience and brain development. Wiley Interdisciplinary Reviews: Cognitive Science, 8: e1387.

Boal, A. (1979). Theatre of the Oppressed. Trans. Ch.A. and M.-O. Leal McBride. New York: Theatre Communications Group. (Originally published in Spanish as Teatro de Oprimido. Buenos Aires: Ediciones de la Flor, 1974).

Burgon, H.L. (2011). 'Queen of the world': Experiences of 'at-risk' young people participating in equine-assisted learning/therapy. Journal of Social Work Practice, 25(02): 165-183.

Christen, M., \& Narvaez, D. (2012). Moral development in early childhood is key for moral enhancement. AJOB Neuroscience, 3(4): 25-26.

Cowell, J.M., \& Decety, J. (2015). Precursors to morality in development as a complex interplay between neural, socioenvironmental, and behavioral facets. Proceedings of the National Academy of Sciences, 112(41): 12657-12662.

Day, L. (2002). 'Putting yourself in other people's shoes': The use of Forum theatre to explore refugee and homeless issues in schools. Journal of Moral Education, 31(1): 21-34.

Decety, J., \& Cowell, J.M. (2014a). The complex relation between morality and empathy. Trends in Cognitive Sciences, 18(7): 337-339.

Decety, J., \& Cowell, J.M. (2014b). Friends or foes: Is empathy necessary for moral behavior? Perspectives on Psychological Science, 9(5): 525-537.

Decety, J., \& Howard, L.H. (2013). The role of affect in the neurodevelopment of morality. Child Development Perspectives, 7(1): 49-54.

Decety, J., \& Yoder, K.J. (2016). Empathy and motivation for justice: Cognitive empathy and concern, but not emotional empathy, predict sensitivity to injustice for others. Social Neuroscience, 11(1): 1-14.

Douglas, T. (2008). Moral enhancement. Journal of Applied Philosophy, 25(3), 228-245.

Eisenberg, N. (2000). Emotion, regulation, and moral development. Annual Review of Psychology, 51(1): 665-697.

Escobar, M.J., Huepe, D., Decety, J., Sedeño, L., Messow, M.K., Baez, S., ... \& Schröeder, J. (2014). Brain signatures of moral sensitivity in adolescents with early social deprivation. Scientific Reports, 4.

Focquaert, F., \& Schermer, M. (2015). Moral enhancement: do means matter morally? Neuroethics, 8(2): 139-151.

Franklin Jr., R.G., Nelson, A.J., Baker, M., Beeney, J.E., Vescio, T.K., Lenz-Watson, A., \& Adams Jr., R.B. (2013). Neural responses to perceiving suffering in humans and animals. Social Neuroscience, $8(3)$ : 217-227.

Gourd, K.M., \& Gourd, T.Y. (2011). Enacting democracy: Using forum theatre to confront bullying. Equity \& Excellence in Education, 44(3): 403-419.

Greene, J.D. (2015a). Beyond point-and-shoot morality: Why cognitive (neuro)science matters for ethics. The Law \& Ethics of Human Rights, 9(2): 141-172.

Greene, J.D. (2015b). The rise of moral cognition. Cognition, 135: 39-42.

Greene, J.D., Nystrom, L.E., Engell, A.D., Darley, J.M., \& Cohen, J.D. (2004). The neural bases of cognitive conflict and control in moral judgment. Neuron, 44(2): 389-400.

Greene, J.D., Sommerville, R.B., Nystrom, L.E., Darley, J.M., \& Cohen, J.D. (2001). An fMRI investigation of emotional engagement in moral judgment. Science, 293(5537): 2105-2108.

Joronen, K., Konu, A., Rankin, H.S., \& Åstedt-Kurki, P. (2011). An evaluation of a drama program to enhance social relationships and anti-bullying at elementary school: a controlled study. Health Promotion International, 27(1): 5-14. 
Klincewicz, M., Frank, L.E., \& Sokólska, M. (2018). Drugs and hugs: stimulating moral dispositions as a method of moral enhancement. In: M. Hauskeller (ed.). Moral Enhancement: Critical Perspectives. Cambridge: Cambridge University Press.

Kohl, R. (2012). Prison animal programs: a brief review of the literature. Massachusetts Department of Correction, Office of Strategic Planning and Research.

Lapsley, D.K., \& Narvaez, D. (2005). Moral psychology at the crossroads. In: K.D. Lapsley, F.C. Power (eds.). Character Psychology and Character Education (pp. 18-35). Notre Dame: University of Notre Dame Press.

Mikhail, J. (2007). Universal moral grammar: Theory, evidence and the future. Trends in Cognitive Sciences, 11(4): 143-152.

Mischel, W., \& Shoda, Y. (1995). A cognitive-affective system theory of personality: reconceptualizing situations, dispositions, dynamics, and invariance in personality structure. Psychological Review, 102(2): 246.

Mitchell, K.S., \& Freitag, J.L. (2011). Forum theatre for bystanders: A new model for gender violence prevention. Violence Against Women, 17(8): 990-1013.

Moll, J., de Oliveira-Souza, R., \& Zahn, R. (2008). The neural basis of moral cognition. Annals of the New York Academy of Sciences, 1124(1): 161-180.

Moll, J., Zahn, R., de Oliveira-Souza, R., Krueger, F., \& Grafman, J. (2005). The neural basis of human moral cognition. Nature Reviews Neuroscience, 6(10): 799.

Nurenberg, J.R., Schleifer, S.J., Shaffer, T.M., Yellin, M., Desai, P.J., Amin, R., ... \& Montalvo, C. (2014). Animal-assisted therapy with chronic psychiatric inpatients: equine-assisted psychotherapy and aggressive behavior. Psychiatric Services, 66(1): 80-86.

Pendry, P., Carr, A.M., Smith, A.N., \& Roeter, S.M. (2014). Improving adolescent social competence and behavior: A randomized trial of an 11-week equine facilitated learning prevention program. The Journal of Primary Prevention, 35(4): 281-293.

Persson, I., \& Savulescu, J. (2008). The perils of cognitive enhancement and the urgent imperative to enhance the moral character of humanity. Journal of Applied Philosophy, 25(3): 162-177.

Persson, I., \& Savulescu, J. (2012). Unfit for the Future: The Need for Moral Enhancement. Oxford: Oxford University Press.

Prinz, J. (2011). Is empathy necessary for morality? Empathy: Philosophical and Psychological Perspectives, $1: 211-229$.

Rodríguez, J.I., Rich, M.D., Hastings, R., \& Page, J.L. (2006). Assessing the impact of Augusto Boal's "Proactive Performance": An embodied approach for cultivating prosocial responses to sexual assault. Text and Performance Quarterly, 26(3): 229-252.

Schaefer, G.O. (2015). Direct vs. indirect moral enhancement. Kennedy Institute of Ethics Journal, 25(3): 261-289.

Specker, J., Focquaert, F., Raus, K., Sterckx, S., \& Schermer, M. (2014). The ethical desirability of moral bioenhancement: a review of reasons. BMC Medical Ethics, 15(1): 1.

Szutta, N. (2015b). Wychowanie moralne z perspektywy etyki cnót. Diametros, 46: 111-133.

Van Bavel, J.J., FeldmanHall, O., \& Mende-Siedlecki, P. (2015). The neuroscience of moral cognition: from dual processes to dynamic systems. Current Opinion in Psychology, 6: 167-172.

Wernick, L.J., Kulick, A., Dessel, A.B., \& Graham, L.F. (2016). Theater and dialogue to increase youth's intentions to advocate for LGBTQQ people. Research on Social Work Practice, 26(2): 189-202.

Winston, J. (1999). Theorising drama as moral education. Journal of Moral Education, 28(4): 459-471.

Young, L., \& Dungan, J. (2012). Where in the brain is morality? Everywhere and maybe nowhere. Social Neuroscience, 7(1): 1-10. 